
\title{
$\begin{array}{ll}\text { Research Square } & \begin{array}{l}\text { Preprints are preliminary reports that have not undergone peer review. } \\ \text { They should not be considered conclusive, used to inform clinical practice, } \\ \text { or referenced by the media as validated information. }\end{array}\end{array}$
}

\section{Open-Circuit Photovoltage Measurements Towards Determination of the Quintessential Features of Metal Titanates in Photo(Electro)catalytic Applications}

\section{Szymon Wojtyła}

Sajtom Light Future

Tomasz Baran ( $\nabla$ tommaso.baran@gmail.com )

SajTom Light Future https://orcid.org/0000-0002-5140-3155

Original Research

Keywords: Semiconductor, photocatalyst, flat band potential, conduction band edge, superoxide anion radical

Posted Date: February 10th, 2021

DOl: https://doi.org/10.21203/rs.3.rs-178220/v1

License: (c) (i) This work is licensed under a Creative Commons Attribution 4.0 International License. Read Full License 


\section{Abstract}

Conduction band potential is one of the most crucial physicochemical properties of semiconductor towards photocatalytic and photoelectrochemical aplications. Inexpensive home-made Arduino devices is proposed for determination of flat band potential, based on the well-established method: open-circuit photovoltage measurements. To verify proposed measurement procedure, series of titanates has been prepared by a straightforward hydrothermal procedure and characterized - band structure of materials has been determined, in terms of band gap energy and conduction band edge potential. Finally we demonstrated the photocatalytic formation of superoxide anion radical. Interestingly, the efficiency of $\mathrm{O}_{2}{ }^{-}$ can be correlated, in part, with the potential of conduction band edge. Photocatalyst characterized by particularly low potential of conduction band edge can generate the superoxide anion radical with highest efficiency.

\section{Introduction}

Photocatalysis and photoelectrochemistry have numerous applications in water splitting, air/water purification or $\mathrm{CO}_{2}$ reduction [1-3]. Fundamental properties and activity of semiconductor-based photocatalysts depend on their electronic band structure. The electrochemical potential of the conduction and/or valence band edges exerts a crucial impact on the activity of the photocatalytic system. Numerous method to estimate these potentials are known e.g. capacitance measurements (MottSchottky plot), photocurrent onset measurements, spectroelectrochemical methods, open-circuit photovoltage measurements, quasi-Fermi level measurements [4-8]. In this paper we described the approach of the flat band potential determination based on the well-established method - open-circuit photovoltage measurements, but using an inexpensive home-made Arduino device.

The understanding of a behavior of semiconductor in electrolyte seems to be crucial in all photoelectrochemical and photocatalytic applications. After the contact of the semiconductor surface with the electrolyte, the Fermi level of the semiconductor $E_{F}$ is adjusted to the Fermi level of the electrolyte $E_{F, \text { redox }}$ [9]. For example, in case of the n-type semiconductors, where $E_{F}$ is higher in energy than $E_{F, \text { redox }}$ it can be achieved through the transfer of electrons from the semiconductor to acceptors in solution. This process has the effect of charging the semiconductor positively, and since semiconductor carrier density is lower than in electrolyte. The diffuse charge in the material is counterbalanced basically by a sheet of charge in the electrolyte [10]. External changing the voltage of the semiconductor results in the separation of $\mathrm{E}_{\mathrm{F}}$ and $\mathrm{E}_{\mathrm{F}, \text { redox }}$, and hence the level of band bending due to electron depletion in the semiconductor depends on the applied voltage. If this external voltage is such that there is no band bending - the semiconductor is at its flat-band potential, $\mathrm{V}_{\mathrm{FB}}$, and there is no net transfer of charge. As mentioned above, the $\mathrm{E}_{\mathrm{FB}}$ can determined from the dependence of the open-circuit potential of semiconductor (OCP) on the irradiation intensity $[6,11]$. Under OCP conditions, the photogenerated holes are accumulating at semiconductor surface, which with increasing light intensity lowers the barrier for photogenerated electrons until the electrons can reach the surface at the same rate as holes. Simultaneously, the quasi- 
Fermi level increases due to the higher occupancy of the conduction band. The quasi-Fermi level can be measured as a OCP [11]. In case of high enough irradiation intensity (Fig. 1), the OCP becomes constant and this value is very close to the potential of the conduction band edge (for n-type semiconductor) or to the potential of the valence band edge (for p-type semiconductor) [11, 12].

In case of high enough irradiation intensity, the OCP becomes constant and this value is very close to the potential of the conduction or valence band edge. Irradiation with increasing light intensity is necessary for this measurement. It can be performed using series of filters or metal wire gauzes [11] that can lower the light intensity, however we propose to use the inexpensive and very simple Arduino-based LED device, that can control the intensity of emitted light (power LED chip on board). Lowering the light intensity can be obtained by PWM (Pulse Width Modulation) dimming. With PWM strings of LED is driven with the recommended forward current, with the dimming achieved by turning the LEDs ON and OFF at high frequency - so fast the human cannot notice the strobing effect. In PWM approach the longer the ON time in respect to OFF periods resulted in the brighter light.

To verify proposed measurement procedure, series of titanates has been prepared by a straightforward hydrothermal procedure and characterized - band structure of materials has been determined, in particular band gap energy and conduction band edge potential. Finally we demonstrated the photocatalytic formation of superoxide anion radical.

\section{Experimental}

\subsection{Synthesis of titanates}

All the reagents used in this procedure were of analytical grade and used without further purification. An appropriative amount of metal precursors (see Table 1) was dissolved in $20 \mathrm{~mL}$ of water. Ethylene glycol $(5 \mathrm{~mL})$ and citric acid $(1.9 \mathrm{~g})$ was added to the solution. Then, $0.568 \mathrm{~g}$ of titanium(IV) isopropoxide, (98+\%, ACROS Organics) was dissolved in $10 \mathrm{~mL}$ of isopropyl alcohol. Titanium solution was added dropwise into metal precursor solution under vigorous stirring condition. The resulting solution was stirred for $1 \mathrm{~h}$ at room temperature and subsequently the mixture was transferred to a Teflon lined autoclave with capacity of $150 \mathrm{~mL}$ and heated at $175^{\circ} \mathrm{C}$ for $12 \mathrm{~h}$. The precipitate obtained was separated by centrifugation, washed with water and ethanol and dried under vacuum. Subsequently all materials were annealed in $500^{\circ} \mathrm{C}$ for $3 \mathrm{~h}$. 
Table 1

List of prepared materials and used precursors

\begin{tabular}{|llll|}
\hline $\mathrm{NiTiO}_{3}$ & Prepared material & Metal precursor & Mass of precursor \\
\hline $\mathrm{CoTiO}_{3}$ & $\mathrm{Ni}\left(\mathrm{CH}_{3} \mathrm{CO}_{2}\right)_{4} \cdot 4 \mathrm{H}_{2} \mathrm{O}$ & $0.498 \mathrm{~g}$ \\
\hline $\mathrm{CuTiO}_{3}$ & $\mathrm{Co}\left(\mathrm{CH}_{3} \mathrm{CO}_{2}\right)_{2} \cdot 4 \mathrm{H}_{2} \mathrm{O}$ & $0.498 \mathrm{~g}$ \\
$\mathrm{ZnTiO}_{3}$ & $\mathrm{Zn}\left(\mathrm{CH}_{3} \mathrm{COO}\right)_{2} \cdot \mathrm{H}_{2} \mathrm{O}$ & $0.399 \mathrm{~g}$ \\
$\mathrm{SrTiO}_{3}$ & $\mathrm{Sr}(\mathrm{OH})_{2} \cdot 8 \mathrm{H}_{2} \mathrm{O}$ & $0.532 \mathrm{~g}$ \\
\hline
\end{tabular}

\subsection{Arduino-based LED controller construction}

The scheme of Arduino-based LED controller is shown in Fig. 2. Device is composed of: Arduino UNO microcontroller, linear potentiometer 10k, driver LED working on 200mA, power supplier 24V DC and power LED (P:4.5W; $\lambda 400 \mathrm{~nm} ; \mathrm{P}_{\text {opt }}: 850 \mathrm{~mW}$, equipped with cooling system). We set the potentiometer pin as $\mathrm{AO}$ ( analog pin). The control variable is the voltage, that is used to control the led brightness. In the setup function the control pin 9 is set as output. In the loop we are getting the analog reading value of the voltage that is applied on pin $\mathrm{A} 0$. Arduino program translate the voltage value in $\mathrm{A} 0$ pin into PWM answer on pin 9 and therefore LED emits the light of intensity depending on the voltage given by potentiometer. Additionally devices can be equipped with a display, that give the actual percentage of light intensity.

\subsection{Photovoltage measurements}

All materials were deposited on fluorine doped tin oxide (FTO) glass. OCP measurements were performed using 2-electrode cell: semiconductor@FTO as a working electrode and $\mathrm{Ag} / \mathrm{AgCl}$ as a reference electrode. The $0.1 \mathrm{M}$ phosphate buffer $(\mathrm{pH}=7)$ was used as an electrolyte. In order to avoid reaction of photogenerated electrons with oxygen dissolved in the electrolyte, which could decrease the OCP, it is necessary to bubble the electrolyte with nitrogen 15 min prior to experiment as well as during measurements. Measurements were controlled by SP-150 Bio-logic potentiostat. Working electrodes were illuminated from backside (to avoid the influence of film thickness) by LED-devices controlled by Arduino microcontroller.

\subsection{Materials characterization and their photoactivity}

Materials' structures were identified using X-ray diffraction (XRD) at X'Pert PRO (X-ray (Cu) 40 kV). Diffuse reflectance spectra (DRS) in were measured using a UV-2600 spectrophotometer (Shimadzu) equipped with an integrating sphere. Previously dried $\mathrm{BaSO}_{4}$ (Sigma-Aldrich) was used to dilute the sample. Samples were ground with $\mathrm{BaSO}_{4}$ in 1:50 wt. ratio. $\mathrm{BaSO}_{4}$ was used also as a reference material. 
Activity of materials were evaluated based on the efficiency of photocatalytic formation of superoxide anion radicals. The formation of superoxide was monitored by using a well-established method, using nitro blue tetrazolium (NBT) assay [13]. The NBT can be reduced by superoxide anion radicals to insoluble purple formazan. The photocatalysts $(1 \mathrm{mg} / \mathrm{mL}$ ) were added into $15 \mathrm{~mL}$ solutions of NBT (10 $\mathrm{mmol} / \mathrm{L}$ ) in cylindrical quartz vessel. Methanol was added as a hole scavenger $(1.5 \mathrm{~mL})$. Mixture was sonicated for $5 \mathrm{~min}$ to disperse the photocatalyst and subsequently suspension was irradiated using XBO lamp under continuous oxygen bubbling. Irradiation was carried out for $60 \mathrm{~min}$. Solution was filtered using nylon syringe filter and measured using UV-2600 spectrometer (Shimadzu).

\section{Results And Discussion}

Photovoltage measurements were performed to determine a flat band potential, that can be associated with conduction band potential $[6,14]$. Figure 3 shows the results of open-circuit photovoltage measurements in case of $\mathrm{NiTiO}_{3}$. Under illumination the OCP shifts to a negative direction. This sign of open-circuit photovoltage points to n-type conductance - typically for mostly titanates $[15,16]$. With increase in the illumination intensity, the OCP approaches a limit of ca. $0.29 \mathrm{~V}$, and OCP becomes independent of intensity when the light intensity exceeds relative values of $70 \%$. In case of high enough irradiation intensity, the OCP becomes constant and this value is very close to the potential of the conduction band edge. Determined $\mathrm{E}_{\mathrm{FB}}$ of $\mathrm{NiTiO}_{3}$ was $+0.29 \mathrm{~V}$ vs $\mathrm{RHE}(\mathrm{pH}=7)$.

Flat band potentials of others titanates were estimated from photovoltage measurements performed in a similar way. Determined flat band potentials of all studied materials are summarized in Table 2, and results are in accordance with literature reports [17]. Good agreement with literature data validate the use of described devices for open-circuit photovoltage measurements towards flat band determination.

Table 2. Determined flat band potentials and band gap energies

\begin{tabular}{|lll|}
\hline Prepared material & Flat band potential vs RHE & Band gap energy \\
\hline $\mathrm{NiTiO}_{3}$ & $0.29 \mathrm{~V} \pm 0.008 \mathrm{~V}$ & $3.08 \mathrm{eV} \pm 0.05 \mathrm{eV}$ \\
\hline $\mathrm{CoTiO}_{3}$ & $0.43 \mathrm{~V} \pm 0.01 \mathrm{~V}$ & $2.40 \mathrm{eV} \pm 0.05 \mathrm{eV}$ \\
\hline $\mathrm{CuTiO}_{3}$ & $-0.11 \mathrm{~V} \pm 0.009 \mathrm{~V}$ & $1.31 \mathrm{eV} \pm 0.05 \mathrm{eV}$ \\
\hline $\mathrm{ZnTiO}_{3}$ & $-0.14 \mathrm{~V} \pm 0.01 \mathrm{~V}$ & $3.28 \mathrm{eV} \pm 0.05 \mathrm{eV}$ \\
\hline $\mathrm{SrTiO}_{3}$ & $-0.77 \mathrm{~V} \pm 0.01 \mathrm{~V}$ & $3.19 \mathrm{eV} \pm 0.05 \mathrm{eV}$ \\
\hline
\end{tabular}

DRS spectroscopy was used to determine the band gap energies of materials. Diffuse reflectance spectra of titanates were transformed to the Kubelka-Munk function (KM), defined as: 
$F_{K M}\left(R_{\infty}\right)=\frac{\left(1-R_{\infty}\right)^{2}}{2 R_{\infty}}=\frac{\alpha(h v)}{s}$

where $R_{\infty}$ is the diffuse reflectance referred to a layer of infinite thickness, $S$ the scattering coefficient and $a$ (hv) the absorption coefficient. The results are shown in Figure 4A-E. Strontium titanate and zinc titanate absorb light only in UV range. In contrast, other titanates showed absorption also in visible light range. The band gap energy $\left(E_{\mathrm{BG}}\right)$ was estimated from the Tauc plot $\left(\left[\mathrm{F}_{\mathrm{KM}}\left(\mathrm{R}_{\infty}\right) \mathrm{E}\right]^{\mathrm{n}} v s\right.$. $\left.\mathrm{E}\right)$ shown in Figure $4 \mathrm{~F}$ (example results - $\mathrm{SrTiO}_{3}$ ) since

$$
(\alpha h v)^{n}=A\left(h v-E_{B G}\right)
$$

where $E$ is the energy of light (photon), while the exponent $n=2$ or $n=1 / 2$ when direct or indirect transitions are allowed, respectively. The values of $E_{\mathrm{BG}}$ of titanates are summarized in Table 2.

XRD analysis was performed to confirm the synthesis of titanates. All XRD patterns are shown in Figure 5. All the diffraction peaks $\left(23.9^{\circ}, 33.0^{\circ}, 35.7^{\circ}, 40.6^{\circ}, 49.0^{\circ}, 53.5^{\circ}, 57.0^{\circ}, 62.1^{\circ}\right.$, and $\left.63.8^{\circ}\right)$ of $\mathrm{ZnTiO}_{3}$ can be indexed to rhombohedral $\mathrm{ZnTiO}_{3}$ according to the JCPDS file numbers 26-1500. Pattern of strontium titanate can be fully ascribed to the cubic perovskite structure of $\mathrm{SrTiO}_{3}$ (JCPDS card 35-0734), with main diffraction peaks: $32.5^{\circ}, 39.9^{\circ}, 46.4^{\circ}, 37.8^{\circ}$, and $67.9^{\circ}$. The obtained cobalt titanate has an imielite structure (JCPDS card No. 77-1373). The main peaks are: 24.0, 33.0, 35.6, 41.0, 49.1, 53.7, 57.0, 62.0, and 63.7 degree. Finally, nickel titanate sample shows XRD peaks, which can be ascribed to the rhombohedral $\mathrm{NiTiO}_{3}$.

Photoactivity of titanates were evaluated based on the efficiency of superoxide anion radicals $\left(\mathrm{O}_{2}^{\left.-{ }^{-}\right)}\right.$ formation. Under irradiation electron and hole pairs can be generated in conduction and valance bands, respectively. Superoxide anion radicals can be formed as illustrated in the following reaction, via reduction of oxygen by photogenerated electrons from conduction band [18]: $\mathrm{O}_{2}+\mathrm{e}_{\mathrm{CB}}^{-} \rightarrow \mathrm{O}_{2}^{-\cdot}$. The formation of $\mathrm{O}_{2}^{--}$was monitored by using a nitro blue tetrazolium (NBT) based technique [13]. Irradiation of all photomaterials lead to a decrease of NBT absorption band at $\mathrm{l}=260 \mathrm{~nm}$, as shown in Figure 6 . This effect is due to the formation of $\mathrm{O}_{2}{ }^{-{ }^{*}}$ and the rate of decrease can be associated with yield of $\mathrm{O}_{2}{ }^{-}$ formation. Experimental data suggest, that the highest efficiency of $\mathrm{O}_{2}{ }^{-{ }^{-}}$formation occur in case of $\mathrm{SrTiO}_{3}$ and $\mathrm{ZnTiO}_{3}$, while the lowest for $\mathrm{CoTiO}_{3}$.

The efficiency of $\mathrm{O}_{2}{ }^{-*}$ can be correlated, in part, with the potential of conduction band edge. The reasons of this correlation is presented in Figure 7. Photocatalyst characterized by particularly low potential of conduction band edge can generate the superoxide anion radical with highest efficiency. Potential of oxygen reduction to superoxide anion radical is equal to $0.56 \mathrm{~V}$ vs RHE and therefore all titanates can perform oxygen reduction to $\mathrm{O}_{2}^{-\bullet}$ according to thermodynamic aspects. However, the higher overpotential may lead to the more efficient $\mathrm{O}_{2}^{-\bullet}$ formation. 


\section{Conclusion}

Series of titanates has been prepared by a straightforward hydrothermal procedure. The most crucial band structure features of semiconducting materials were determined, in principle band gap energy and conduction band potential. In this paper we described the approach of the conduction band edge determination based on the well-established method - open-circuit photovoltage measurements, but using an inexpensive home-made Arduino devices. Finally we demonstrated the photocatalytic formation of superoxide anion radical. Interestingly, the efficiency of $\mathrm{O}_{2}^{-*}$ can be correlated, in part, with the potential of conduction band edge. Photocatalyst characterized by particularly low potential of conduction band edge can generate the superoxide anion radical with highest efficiency.

\section{Declarations}

Acknowledgments

This work was co-financed from European Funds from the Regional Operational Program of the Lesser Poland Voivodship for the years 2014-2020 (grant no. RPMP.01.02.01-12-0401/17-00).

All authors contributed equally to this work. No conflict of interest to declare.

\section{References}

1. M. Grätzel, Nature 414, 338 (2001).

2. S. Wojtyła, W. Macyk, and T. Baran, Photochem. Photobiol. Sci. 16, 1079 (2017).

3. M. Aresta, A. Dibenedetto, T. Baran, S. Wojtyła, and W. Macyk, Faraday Discuss. 183, 413 (2015).

4. A. M. Roy, G. C. De, N. Sasmal, and S. S. Bhattacharyya, International Journal of Hydrogen Energy 20, 627 (1995).

5. J. R. White and A. J. Bard, The Journal of Physical Chemistry 89, 1947 (1985).

6. R. Beranek, Advances in Physical Chemistry 2011, e786759 (2011).

7. T. Baran, S. Wojtyła, C. Lenardi, A. Vertova, P. Ghigna, E. Achilli, M. Fracchia, S. Rondinini, and A. Minguzzi, ACS Appl. Mater. Interfaces 8, 21250 (2016).

8. G. Redmond and D. Fitzmaurice, J. Phys. Chem. 97, 1426 (1993).

9. M. X. Tan, P. E. Laibinis, S. T. Nguyen, J. M. Kesselman, C. E. Stanton, and N. S. Lewis, in Progress in Inorganic Chemistry, edited by K. D. Karlin (John Wiley \& Sons, Inc., 1994), pp. 21-144.

10. K. Gelderman, L. Lee, and S. W. Donne, J. Chem. Educ. 84, 685 (2007).

11. Y. V. Pleskov, V. M. Mazin, Y. E. Evstefeeva, V. P. Varnin, I. G. Teremetskaya, and V. A. Laptev, Electrochem. Solid-State Lett. 3, 141 (2000).

12. R. Morrison, Electrochemistry at Semiconductor and Oxidized Metal Electrodes (Plenum Press, New York, 1980). 
13. Y. Nosaka and A. Y. Nosaka, Chem. Rev. 117, 11302 (2017).

14. A. Hankin, J. C. Alexander, and G. H. Kelsall, Phys. Chem. Chem. Phys. 16, 16176 (2014).

15. P. Salvador, C. Gutiérrez, and J. B. Goodenough, Journal of Applied Physics 53, 7003 (1982).

16. T. Baran, S. Wojtyła, A. Vertova, A. Minguzzi, and S. Rondinini, Journal of Electroanalytical Chemistry 808, 395 (2018).

17. Y. Xu and M. A. A. Schoonen, American Mineralogist 85, 543 (2000).

18. V. Diesen and M. Jonsson, J. Phys. Chem. C 118, 10083 (2014).

\section{Figures}

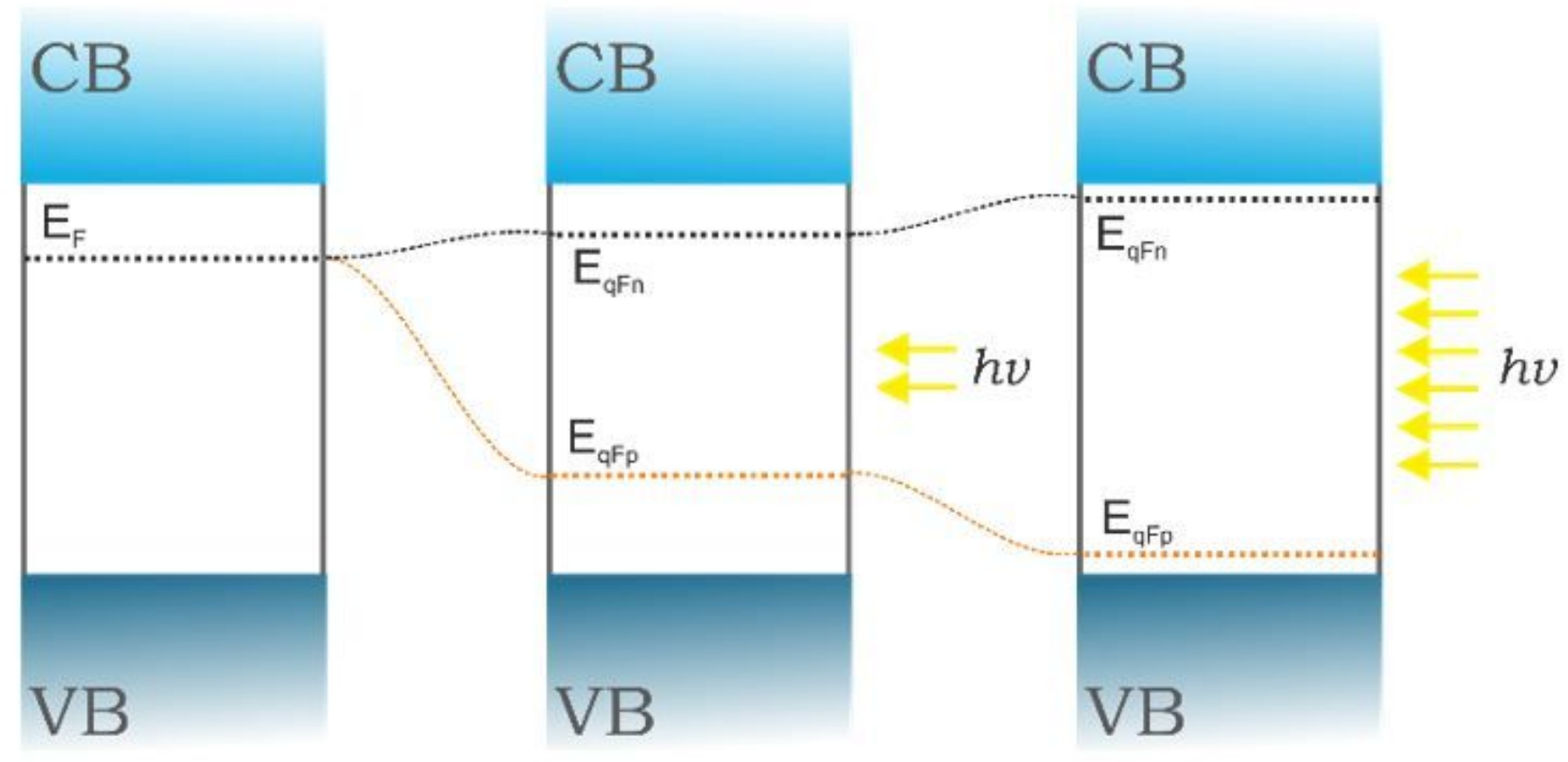

Figure 1

Fermi levels and quasi-Fermi levels of electrons for an n-type semiconductor and holes electrons for an $\mathrm{p}$ type semiconductor : in the dark or under illumination - the number of yellow arrows indicate the intensity of light. 

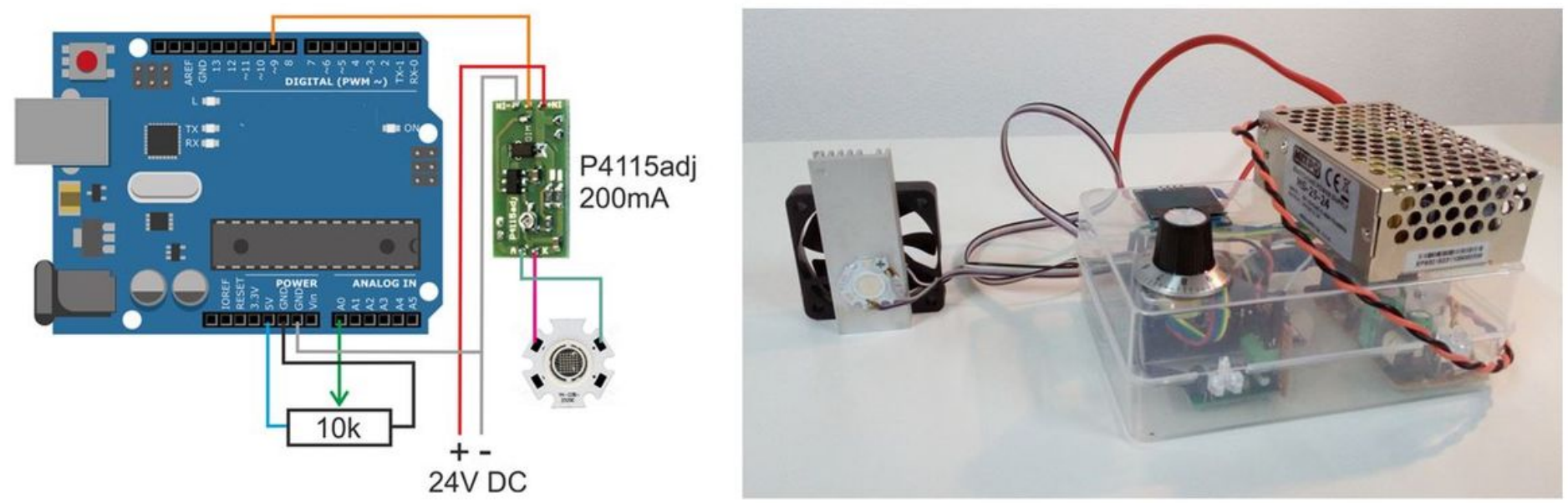

Figure 2

Scheme of Arduino-based LED controller composed of: Arduino UNO microcontroller, linear potentiometer 10k, driver LED (200mA - 700mA PWM/Lin ADJ), power supplier 24V DC and power LED (P:4.5W; $\lambda 400$ nm; Popt:850mW - OPTOSUPPLY OSV4D6CAC1E). Simplified scheme without display. On the right: the photo of device.
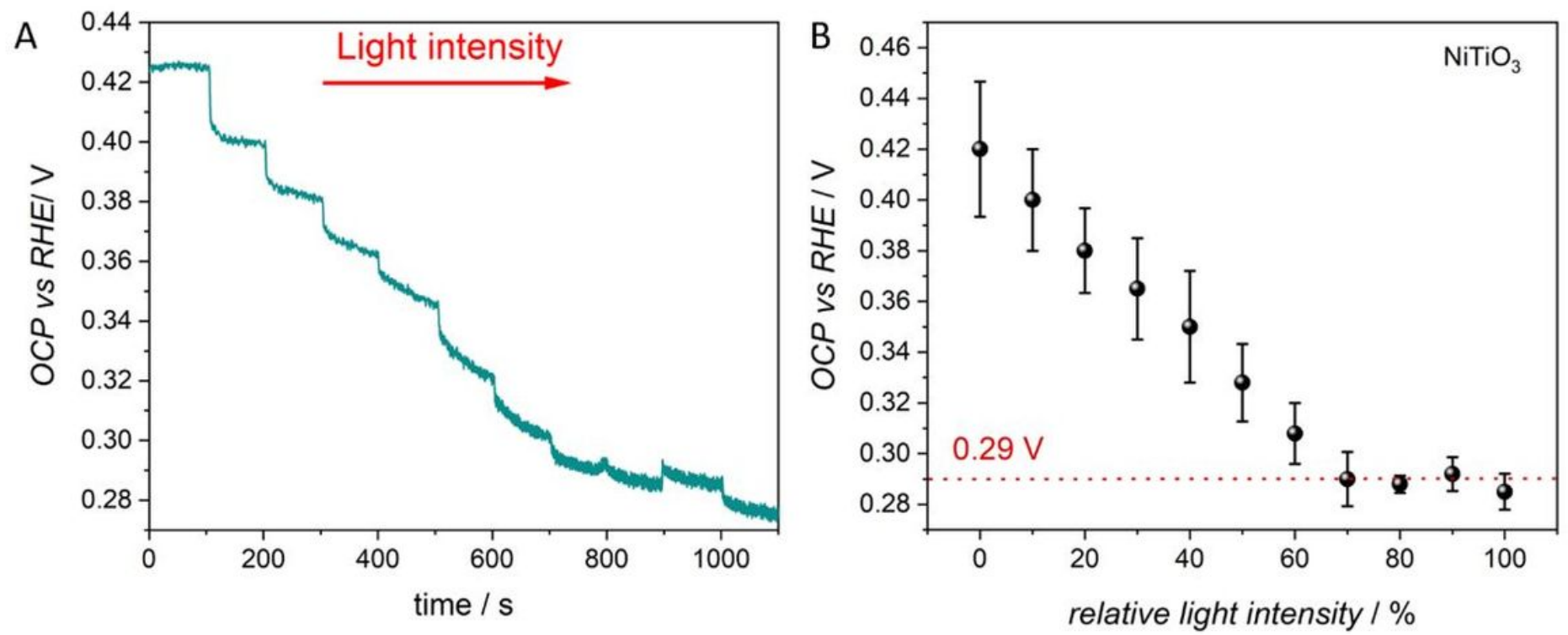

\section{Figure 3}

Dependence of the open-circuit potential (OCP) on illumination intensity measured in electrolyte of $\mathrm{pH}=$ 7. ElectrodeNiTiO3@FTO. A - photovoltage measurement. B - determination of flat band. Error bars are calculated based on the three independent measurements. 

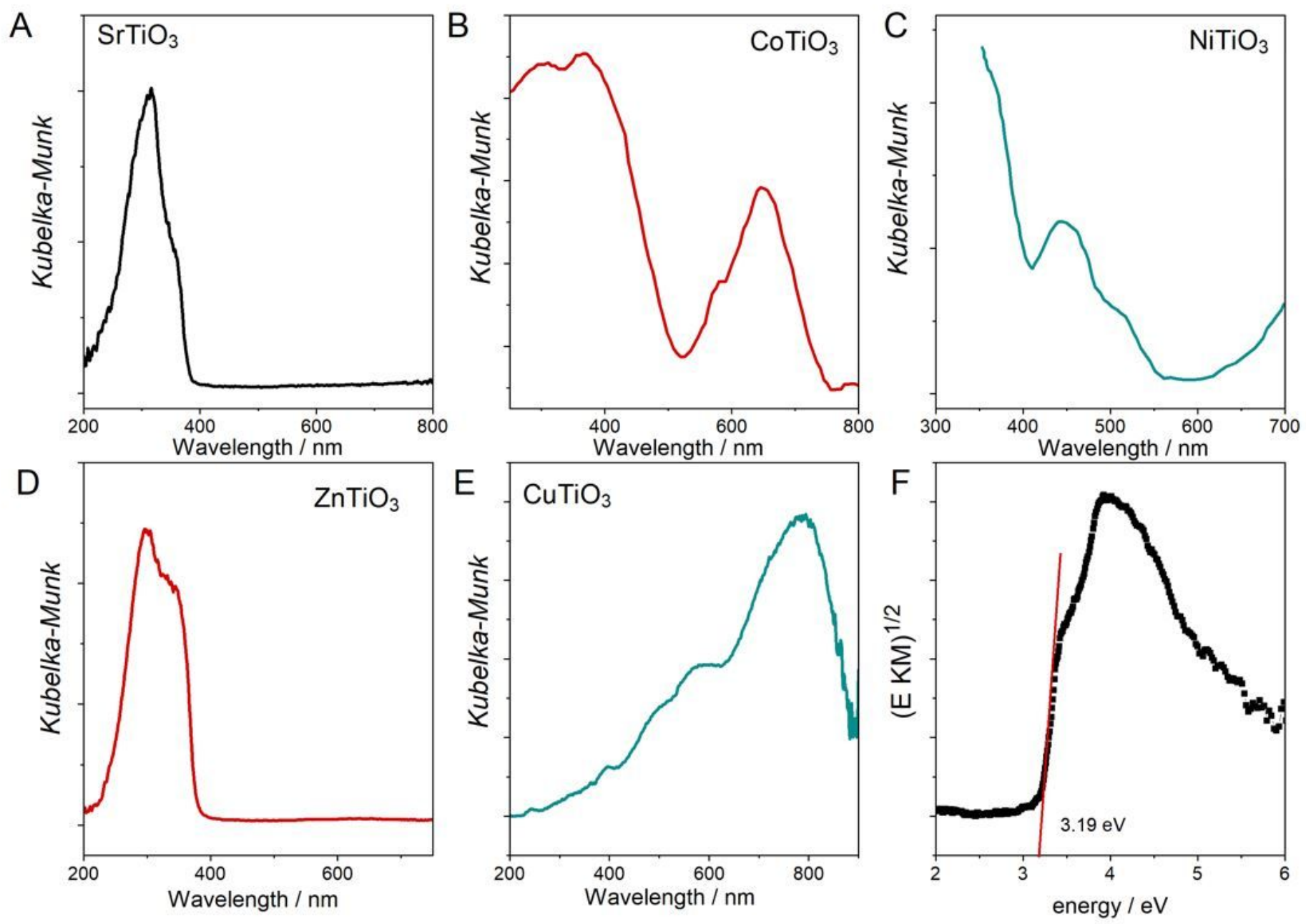

Figure 4

Diffuse reflectance measurements. A-E - Kubelka-Munk functions of all titanates. F - determination of band gap from Tauc plot (SrTiO3). 


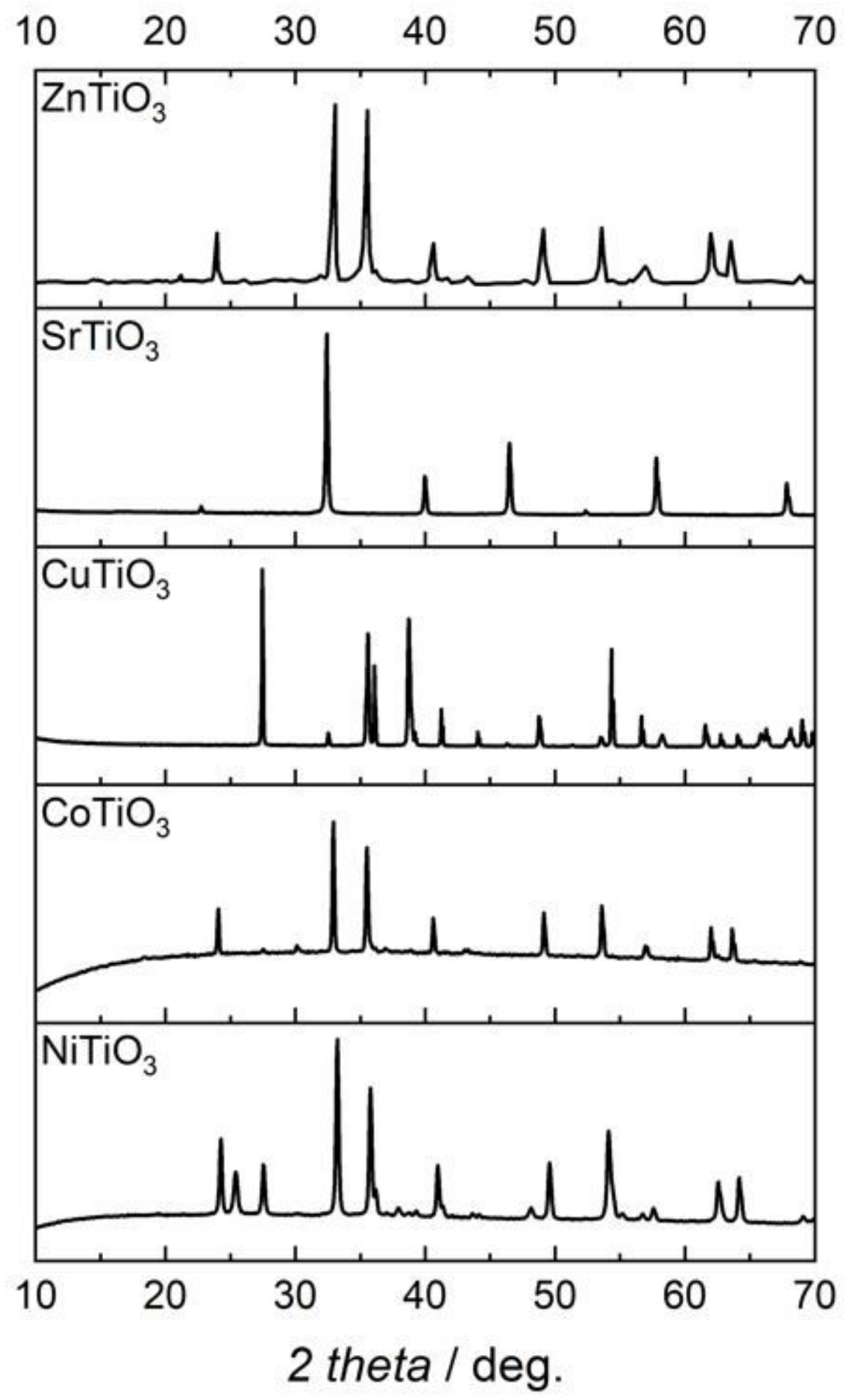

Figure 5

XRD patterns of ZnTiO3, SrTiO3, CuTiO3, CoTiO3, and NiTiO3 

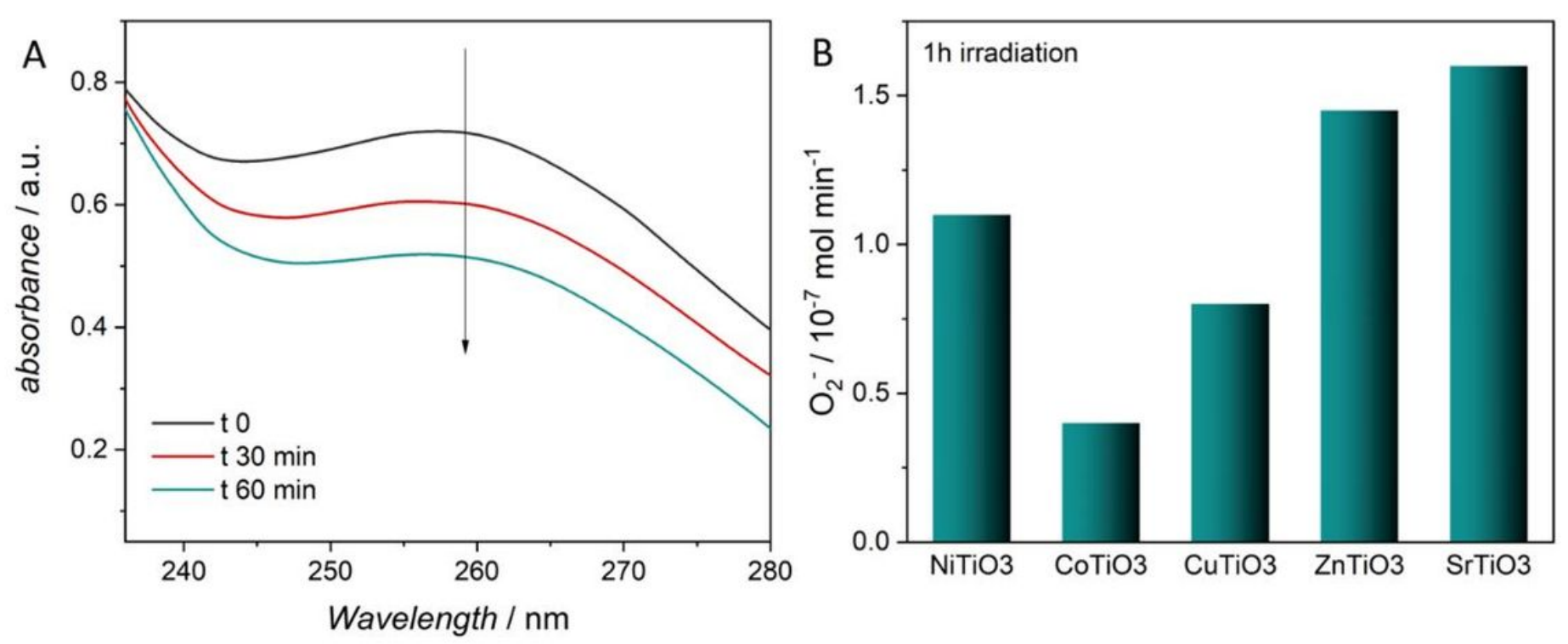

Figure 6

Formation of superoxide anion radical. A - degradation of nitro blue tetrazolium sensors in case of NiTiO3. B - comparison of efficiency of O2-• formation at ZnTiO3, SrTiO3, CuTiO3, CoTiO3, and NiTiO3 during $1 \mathrm{~h}$ irradiation. Results based on tests with NBT.

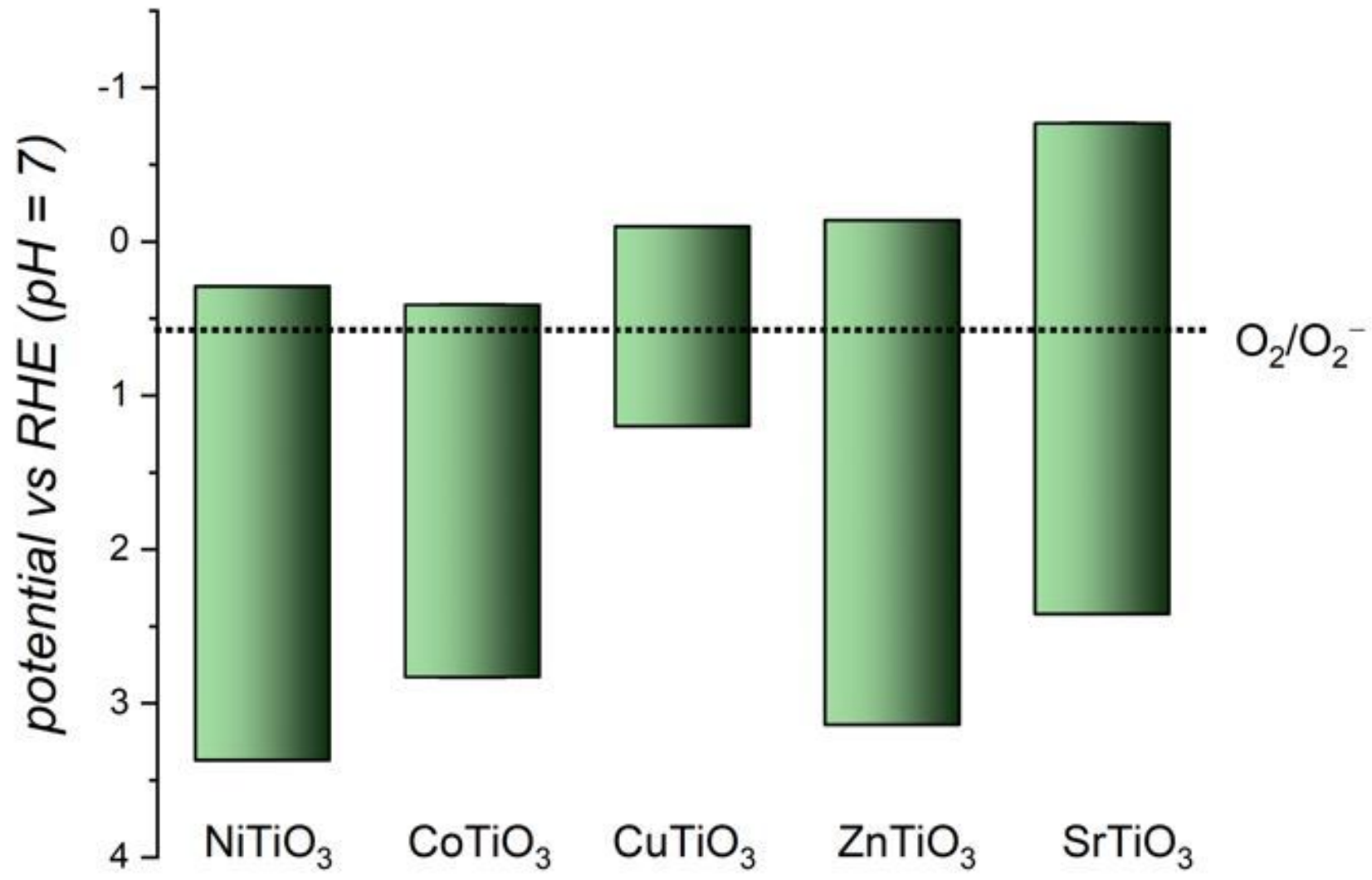


Figure 7

Representation of band structure of titanates. Top of the column represents the conduction band edges, while its height is defined by band gap energy.

\section{Supplementary Files}

This is a list of supplementary files associated with this preprint. Click to download.

- graphicsabstract.jpg 